\section{Bob Willmott}

is the strategy lead for CRM and customer insight at Somo, the world's largest full-service mobile solutions specialist. He supports clients in developing mobile-first strategies to harness the opportunities around loyalty and shopper insights. Previously, he was part of the UK founding team of emnos, the analytics and loyalty consultancy acquired in 2011 by American Express.

Keywords: mobile marketing, loyalty, retail

\section{Opportunities for forward-thinking brands}

\section{Business Intelligence}

\section{Retail showrooms, mobile sales}

\section{Bob Willmott}

Received (in revised form): 15th January 2014

\begin{abstract}
Consumer behaviour is changing as a result of the adoption of smartphones, in particular the way individuals shop. This article considers the way in which 'showrooming' - considering goods in a retail outlet and then purchasing them online - is moving into the mainstream, and suggests marketing strategies that retailers might adopt to cope with this shift.

Journal of Direct, Data and Digital Marketing Practice (2014) 15, 229-232. doi:10.1057/dddmp.2014.4
\end{abstract}

\section{Connecting with the mobile consumer}

Mobile offers the opportunity for a revolution in customer loyalty management, providing the last piece in the jigsaw of connectivity to individuals at the point of purchase. With 64 per cent of consumers now researching products on mobile, ${ }^{1} \mathrm{UK}$ smartphone penetration moving north of 70 per cent and price comparison just a click away, getting their mobile strategy right to harness the many opportunities has become a priority for forward-thinking brands.

That said, it is also easy to see why many column inches have been devoted to the further threat to the High Street from mobile. For many retail brands, mobile threatens to undermine the fundamental tenets upon which their loyalty has been built (see Figure 1). Particularly where price is

\section{- BETTER PRICE \\ - BETTER QUALITY • BETTER SERVICE AGREEMENT}

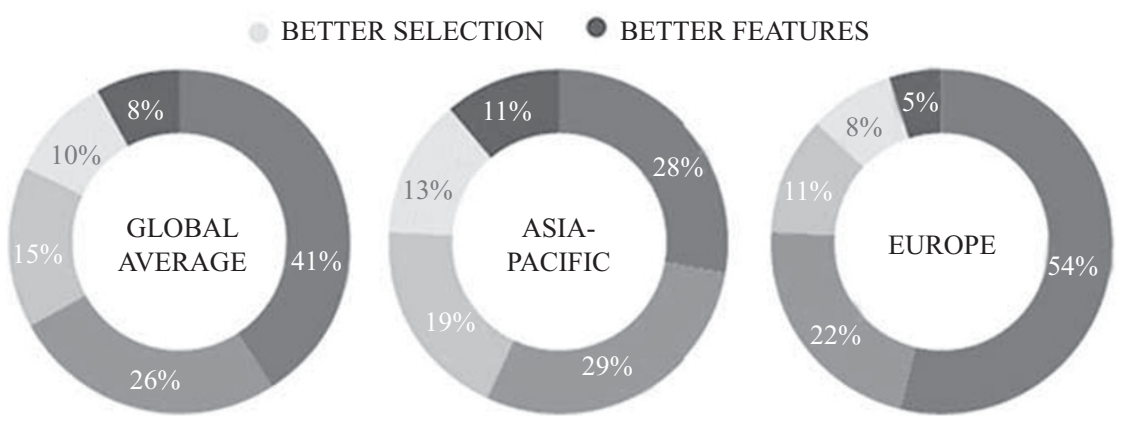

Figure 1: What attribute would encourage you to switch your choice of brand, retailer or service? Source: Nielsen 2013 Global Survey of Loyalty Sentiment, Q1 2013, selected regions http://be.fr.nielsen.com/site/documents/NielsenGlobalReportofLoyaltySentimentNovember2013.pdf 


\section{Using mobile in-store}

\section{Rethinking the approach to retail}

\section{Location-based and anonymous}

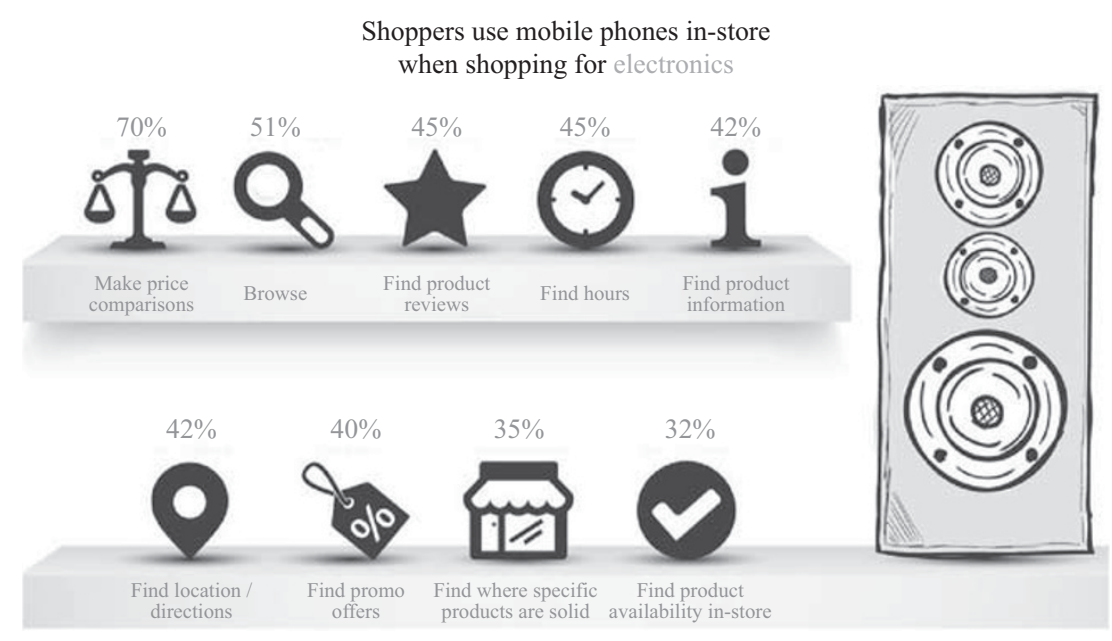

Figure 2: Google Shopper Marketing Council, Q4 2012 Source: 1,500 Smartphone users who use their phone whilst out shopping http://www.google.com/think/research-studies/mobile-in-store.html

the leading factor driving purchase, the ability to price-check via mobile is a major concern.

\section{'Showrooming' goes mainstream}

There is no doubt that 2014 will see further mainstreaming of trends such as 'showrooming'. In its narrowest sense, this describes the growing trend for shoppers to use the High Street and shopping malls to touch, feel and try products, only to go on to purchase online. More broadly, it could encompass the whole range of actions that shoppers undertake on their smartphones while in-store, as highlighted in Figure 2. 54\% of all UK shoppers are showrooming ${ }^{2}$ — and in high ticket sectors such as electronics, price comparison is store has been reported as high as $70 \%$ (of active Smartphone users).

\section{Extending the reach of loyalty}

There are major opportunities for forward-thinking retailers to fundamentally rethink their approach, embracing mobile to establish new grounds of competitive advantage.

Looking specifically at loyalty, the bigger opportunity is to open up new functionality that sees a better integration of loyalty within the wider customer journey, not just an extension of a plastic card scheme.

There are five key advantages for mobile-first relationship programmes and shopper marketing:

1. Mobile adds greater context to the customer situation

- It enables retailers to understand more about an individual customer's behaviour and location, allowing them to make the content, tone and timing of their messaging more relevant to that individual. As 
importantly, it can be delivered via device-tracking, giving the option of collecting anonymous data (to allay any privacy concerns).

- The rollout of iBeacons (and Bluetooth low-energy beacons generically) super-charges these opportunities for 2014. Micro-locational targeting within specific stores/aisles as well as within malls or High Streets becomes a reality. At a cost of less than US $\$ 1$ per beacon, this is more likely to see rapid return on investment than previous store-installed technology.

\section{Giving bricks and mortar a mobile advantage}

\section{Real-time segmentation}

\section{Transform engagement with shoppers at POS}

2. Fuse the power of web analytics with in-store shopper behaviours

- Mobile devices provide the opportunity for bricks and mortar stores to access the level of customer insight and sophistication that has given web companies such an advantage in recent years. Companies such as Euclid in the United States mark the first of a generation offering a new window into the store environment by analysing shopper movements through store, dwell times and so on. Like dunnhumby's innovative use of Tesco data back in the late 1990s, these mobile data innovations represent a similar opportunity for 'smart retail', to deliver service and operating efficiency at the bricks and mortar level.

3. A service nirvana where high-value customers or prospects can be identified within the store environment

- Smartphone functionality opens up the opportunity of differentiated service, of tiered pricing, or the ability to discount in reaction to a consumer showrooming in-store. This could be based on a score that is linked to the profile on a specific device, looking at current and potential future value.

- Spaaza has already run UK pilots with White Stuff where consumers scanning a product code in-store are given a personalized price-point based on a series of profile features.

4. More creative engagement at the point of purchase

- Are Clubcard vouchers, mailed weeks after a purchase, or even Catalina vouchers on a till slip post check-out, part of a past era of shopper marketing?

- We live in the age of instant gratification. Mobile offers the opportunity to engage in the browsing phase with a broader, creative range of rewards - not necessarily points-for-prizes, cashback or discounts. Major brands are now trialling triggers (via scanning, audio, etc) that then offer video, music or games as rewards via the smartphone.

5. Mobilized data brings CRM opportunities to the High Street

- Many loyalty marketers engage with customers only post purchase and, even then, have a limited view of their value potential or broader share-of-wallet. 


\section{Avoiding the offer blizzard}

- Where have customers been searching (online) or shopping (physically) before that initial purchase? What share of wallet are you gaining from your current shoppers? Mobile again provides the connection to bring that data into the bricks and mortar store, linking via registration, Facebook or Twitter IDs and so on.

\section{It's only the beginning of the journey}

There is no doubt that this is still early in the journey for smartphones and tablets. In the era of the empowered consumer, people will make their own choices around which services to download, what their comfort level is around data usage and privacy and so on. Retailers and brands will need to work out ways to avoid an 'offer blizzard' every time a smartphonecarrying shopper hits the High Street, alongside a fairly substantial reinvestment in store-scanning and other technology.

But already markets such as China and, to some extent, the United States are showing a glimpse of the future. In China, 39 per cent of online shoppers are using a tablet for their purchases and 56 per cent are going direct to brand sites to make purchases (52 per cent in the United States). The retail landscape is shifting fast, and retailers and brands alike need to overcome the fear factor and embrace the multiple opportunities.

\section{References}

1. Walker Sands. (2013) 'Reinventing retail: What businesses need to know for 2014', available at http://www.walkersands.com/futureofretail.

2. Mark Donovan. (2013) ComScore MobiLens report. 